\title{
Reflexão de um docente em formação inicial: a dificuldade na leitura' ${ }^{1}$
}

Cassiano Figueiredo Pereira ${ }^{2}$

\section{RESUMO}

Este artigo apresenta algumas reflexões acerca do meu desinteresse pela prática da leitura, que pode refletir na minha formação docente. Essas reflexões foram baseadas nas teorias de Vygotsky (1998, 2008), Wallon (2008), Freire (1989), Chartier (1985, 1990), e para melhor entender o contexto interacional dos dados coletados alinheime a Bateson ([1972], 2002) e Bastos (2005). Trata-se de uma pesquisa qualitativa fundamentada em um dos princípios da Prática Exploratória, na busca de entendimento em detrimento de resultados objetivos (Grupo da Prática Exploratória, 2020). Os dados foram gerados através do diálogo gravado entre minha mãe e mim para tentar levantar os motivos que possam ter me levado ao desinteresse pela leitura.

PALAVRAS-CHAVE: prática de leitura. reflexões. construir entendimentos.

\begin{abstract}
This article presents some thoughts about my difficulty in reading that might reflect in my teacher training. These thoughts were based on the theories of Vygotsky (1998, 2008), Wallon (2008), Freire (1989), Chartier (1985, $1990)$, and to better understand the interactional context of the data collected I consulted Bateson $([1972], 2002)$ and Bastos (2005). This research is qualitative and based on one of the principles of the Exploratory Practice to seek knowledge instead of objective results (Grupo da Prática Exploratória, 2020). The data emerged from a recorded conversation between my mother and I, which I used to try to analyze the reasons that might made me dislike reading.
\end{abstract}

KEY WORDS: reading practice. reflections. knowledge building.

\section{Introdução}

A leitura possibilita ampliar o conhecimento sobre diversos assuntos, porém, para algumas pessoas, mesmo que o desejo de buscar mais entendimentos por meio da leitura seja grande, a realidade pode ser outra. Acredita-se que a prática de leitura deve ser estimulada desde a infância para que a criança cresça acostumada a escutar e discutir sobre as histórias lidas, pois não basta decodificar os códigos de leitura, a interpretação também deve ser levada em consideração. Sendo assim, a formação do leitor começa desde pequeno e se desenvolve ao longo de sua vida.

Supõe-se que os estudantes de graduação em ciências humanas estão preparados para leituras longas e, mesmo passando por um período de adaptação, às vezes alguns deles permanecem relutantes para leitura de textos longos ou complexos. No entanto, buscar entender as dificuldades que estes enfrentam, talvez possa esclarecer e facilitar sua formação de leitores.

\footnotetext{
${ }^{1}$ Agradeço imensamente à Prof. ${ }^{a}$ Me. Michelle Silva de Mattos por ter auxiliado na revisão deste artigo.

${ }^{2}$ Graduando do curso de Letras Português e Inglês pelo Instituto Superior Anísio Teixeira (ISAT) e orientado pela Prof. ${ }^{a}$ Me. Emanuelle Souza Fonseca.
} 
É nessa pesquisa autoetnográfica que busco compreender os motivos que podem ter contribuído para o meu desinteresse na prática de leitura desde a minha infância. A contribuição dessa pesquisa será mútua, pois não será somente para autocompreensão, mas também para aqueles que porventura se identifiquem com esta pesquisa.

Sabe-se que as disciplinas do curso de Letras exigem muitas leituras; logo, esse deve ser um hábito constante. Nesse sentido, surgiram as seguintes inquietações: Por que um docente em formação inicial não gostar de ler? Por que motivar os estudantes a ler se não gosto? Mesmo me questionando sobre minha formação docente, não desanimo, porque acredito que esses questionamentos irão me tornar um profissional consciente que busca melhorar a prática.

Apesar de nós professores, na maioria das vezes, não termos reconhecimento pela contribuição na educação dos indivíduos, estamos sempre em busca de respostas para os nossos questionamentos, nós queremos sempre entender os porquês. Esses porquês estão diretamente ligados às nossas práticas educacionais para uma melhor qualidade de vida em sala de aula.

Como docente em formação inicial, busco entender os motivos que me levaram ao desinteresse da leitura e o que tudo isso pode refletir na minha formação. Nesta pesquisa qualitativa interpretativista, a qual se baseia na prática social e nas interpretações do pesquisador, busco refletir sobre minha prática de leitura.

\section{Fundamentação teórica}

Inicialmente, alinhei-me à teoria de Wallon (2008) e Vygotsky (1998, 2008), partindo do pressuposto de que os indivíduos se constituem na interação social. Orlando e Leite (2018) explicam que dessa maneira é possível internalizar as práticas de uma comunidade. Nesse sentido, podemos compreender a leitura como uma prática, ou seja, ela pode fazer parte da cultura de qualquer indivíduo. Se ele está inserido em uma comunidade onde a prática de leitura não é vista como parte da cultura; logo, não haverá interação social, nem mesmo internalização desse hábito.

Orlando e Leite (2018) expõem, na perspectiva de Wallon (2008), que o indivíduo é considerado como "pessoa" somente por meio do contato social, sendo visto como sujeito único somente quando faz trocas interativas com o "outro". Os autores complementam que, para Vygotsky (1998, 2008), o indivíduo se constitui através da interação social e assimila os valores, as ideias, as práticas de sua cultura por meio do processo de internalização. As pessoas interagem entre si e vivenciam uma cultura, que é externa, e internalizam o que para elas é significativo. Sendo assim, surge seu universo simbólico, ou seja, sua subjetividade. 
A cultura que experienciei quando pequeno não tinha a leitura como prática; sempre tive em mente que a leitura era algo obrigatório da escola, nunca a vi como prazerosa. Por muito tempo, eu não compreendia esse universo como significativo, porque as pessoas com quem eu interagia não tinham esse hábito, e consequentemente, nossas conversas não giravam em torno da leitura. Sobre esse aspecto, Vygotsky $(1998,2008$, apud Orlando e Leite, 2018) afirma que trazemos para o nosso universo simbólico o que é externo a nossa cultura.

Tendo em mente que é a partir da interação social que o sujeito aprende a ler, Grotta (2000) afirma, por meio da linha de pensamento de Wallon (1968), que a afetividade está presente na interação entre as pessoas. Nesse sentido, elas podem carregar experiências positivas ou negativas em relação à leitura. Além disso, o ambiente cultural e social interfere diretamente em sua busca por novas experiências, influenciando na sua busca pela leitura. Assim, essa atividade é rodeada de vínculos afetivos, pois são os motivos, as necessidades e os desejos que levam o sujeito a se interessar pela leitura.

Vale enfatizar, por meio do discurso de Paulo Freire (1989), que a leitura não se limita à decodificação da palavra ou linguagem escrita, mas ela se faz na "inteligência de mundo". Antes da leitura da palavra, ocorrerá a leitura de mundo do leitor, ou seja, da sua realidade, do mundo particular que o move.

Outro aspecto importante apontado por Freire (1989) é o cuidado em relação à quantidade excessiva de páginas de livros solicitados pelos professores aos estudantes, uma vez que alguns tendem a acreditar que as "lições de leitura" de inúmeras páginas ajudarão de fato o estudante a ler. $\mathrm{O}$ autor complementa que a qualidade deve ser levada em consideração, e não a quantidade, ou seja, os textos devem ser compreendidos, lidos minuciosamente, assim evitando memorizá-los de uma maneira forçada.

Sabemos que o foco desta pesquisa não é a escrita; todavia, é indispensável abordar a leitura e não comentar sobre a escrita, uma vez que uma complementa a outra, pois sabe-se que um bom escritor é um leitor ávido (PINKER, 2016). Mas o que Freire quis enfatizar é que vale o professor trabalhar a escrita por meio de textos com cujos assuntos os alunos estejam familiarizados, para que assim seja um aprendizado dinâmico, "vivo", e não estável. Em outras palavras, os estudantes devem aprender na prática, e não simplesmente memorizar o que está sendo ensinado a respeito da escrita.

Orlando e Leite (2018) propõem a compreensão do sujeito como um ser históricocultural, por meio da abordagem histórica de Chartier (1985, 1990), que foca nos costumes, nas práticas de leitura, e na relação do leitor com a comunidade em que está inserido. Nesse sentido, as convenções e o hábito de leitura de uma comunidade podem interferir na liberdade do leitor. 
Sob essa perspectiva, não existe uma "multiplicidade de formas de leitura ilimitada", porque o leitor é influenciado pela comunidade em que está inserido. Sendo assim, a experiência particular é interferida pelo que o torna semelhante à comunidade.

\subsection{A qualidade de vida fora da sala de aula}

$\mathrm{O}$ ato de refletir sobre a prática docente fora da sala de aula pode ser visto como uma postura investigativa na Prática Exploratória (PE) (ALLWRIGHT; HANKS, 2009), uma vez que não se busca construir entendimentos para solucionar problemas, mas sim buscar entendimentos mais profundos. Os praticantes exploratórios apresentam os princípios norteadores da PE como uma maneira de representar tanto o que eles fazem como as reflexões do grupo sobre o entendimento dessa prática (MILLER et al, 2008, p.147). Esses princípios são os seguintes:

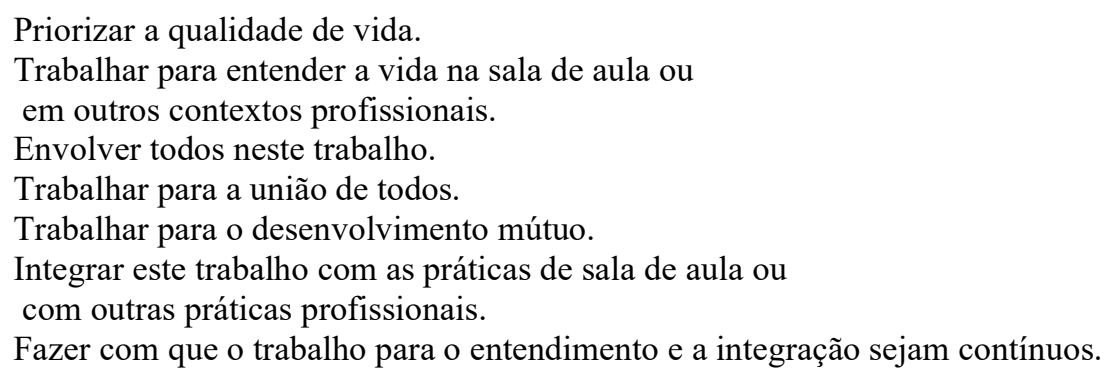

Pelo fato desta pesquisa ser voltada ao sujeito (eu), sem o envolvimento direto de outros participantes (os estudantes), tentei me alinhar ao primeiro princípio da PE, a qualidade de vida. O primeiro passo do praticante exploratório é buscar os porquês que emergem das suas inquietações, para depois refletir sobre elas. Não necessariamente o professor precisa estar dentro da sala de aula para investigar suas questões, o que se pode confirmar com a citação do e-book intitulado Porque trabalhar para entender a vida em sala de aula? "professores e alunos podem investigar suas questões individuais ou de grupo/turma." (GRUPO DA PRÁTICA EXPLORATÓRIA, 2020, p.15).

De acordo com Miller et al. (2008), ao passo que o processo reflexivo ganha força, ele é aprofundado e chama a atenção do praticante exploratório para entender os porquês de aspecto positivo ou não. A partir daí, surgem os puzzles (as questões), que dão direcionamento aos estudos e as reflexões do grupo. 


\subsection{Elementos importantes da interação}

Muitas áreas das ciências humanas e sociais têm se interessado pelas "histórias de vida" presente nas narrativas, como por exemplo a Psicologia Social, a História, a Literatura, a Linguística Aplicada e a Sociolinguística. Bastos (2005) comenta que as "histórias de vida" compartilhadas pelo indivíduo não falam somente dele, mas também de sua compreensão do mundo e de suas experiências nele.

Em uma entrevista de pesquisa pode acontecer de estórias ${ }^{3}$ serem narradas pelo entrevistado, o que pode contribuir para o entendimento da pesquisa. Desta forma, segundo Bastos (2005), a narrativa, sendo vista como uma prática social e preenchida de estórias, "pode nos ajudar a compreender como os indivíduos, na interação com os outros, co-constroem tanto suas identidades quanto a ordem social que os cerca" (BASTOS, 2005, p.75). Segundo a autora, o estudo da narrativa, na Sociolinguística, iniciou-se com Labov e Waletzky (1967) e Labov (1972), que definiram a narrativa como um fato específico do passado, e para ser considerada como tal deve ter uma sequência temporal, um ponto e ser contável.

O entrevistado ao compartilhar uma estória precisa de um motivo para contá-la para que não fuja do contexto e não seja um evento aleatório - isso é o que Labov (1972, apud Bastos, 2005) chama de ponto. Além disso, a narrativa precisa ser contável e se referir a algo extraordinário, que esteja fora de uma rotina, da normalidade, e que chame a atenção de quem está ouvindo. Bastos (2005) explica que deve haver um equilíbrio entre reportabilidade e credibilidade na narrativa, pois no caso um evento muito extraordinário fora da realidade de todos (tanto do falante quanto do ouvinte), acaba perdendo a credibilidade.

Embasando-se na formulação de Labov (1997), Bastos (2005) esclarece que há elementos na narrativa classificados como opcionais e obrigatórios. Normalmente, começa-se narrando uma estória de forma breve, o que não é obrigatório. Em um caso de assalto, por exemplo, o falante pode dizer algo como "pessoal, quase fui assaltado! Sorte que escondi o celular a tempo!”, com o intuito de resumir o evento, e em seguida, ocorre a orientação, em que o ouvinte espera o falante contextualizar o evento que será relatado apontando o que aconteceu, isto é, as pessoas envolvidas, circunstâncias, lugar e tempo. O falante do assalto pode complementar dizendo "ontem à noite saindo da faculdade, eu estava sozinho, a Zé Garoto vazia e escura, quando um cara estranho chegou e..." a fim de situar o ouvinte do que será narrado. Por outro lado, o segundo elemento obrigatório, começa pela ação complicadora, que

\footnotetext{
${ }^{3}$ Bastos (2005) mantém estória com "e", porque se trata de relatos reais que transmitem o que somos, como nos relacionamos e compreendemos o mundo em que estamos inseridos.
} 
consiste na sequência dos enunciados no passado, situa os eventos em ordem cronológica, e caso mude a sequência, o sentido também muda. Após a ação complicadora pode ocorrer a resolução da narrativa, ou seja, a parte em que o evento é finalizado e o ouvinte pode fazer uma pergunta no intuito de querer saber o desfecho do ocorrido "o que aconteceu, afinal?" ou o falante pode ir direto ao ponto final do evento "escondi o celular e apertei o passo.".

Acerca da sequência de orações narrativas, Labov (1997, apud Bastos, 2005) esclarece que a narrativa deve ter no mínimo duas orações numa sequência temporal, o que ele chama de narrativa mínima. $\mathrm{O}$ falante ao contar sua estória pode transmitir um "clima emocional” ou uma "carga dramática", que indica o ponto e a reportabilidade da narrativa. O autor chama esse elemento de avaliação, por exemplo quando o falante ao concluir sua estória diz que estava "aterrorizado, muito nervoso" com a situação.

Bastos (2005) explica que há dois tipos de avaliação, a primeira seria a avaliação externa, que ocorre quando o falante interrompe o fluxo da narrativa para dizer que estava "muito nervoso" e para explicar o porquê dessa emoção no evento reportado. Já a segunda, a avaliação encaixada, segue o fluxo da narrativa e utiliza intensificadores lexicais ("eu estava muito nervoso"), ocorrendo o alongamento das vogais como uma forma de intensificá-las, acelerando ou diminuindo o ritmo da fala, aumentando ou abaixando o tom da voz ("eu estava muiiiiito nervoso") e repetições ("eu estava muito muito nervoso").

A coda seria o último elemento da narrativa, aqui o falante conclui dizendo "e foi isso!", “foi isso que aconteceu!", o ouvinte entende que a narrativa acabou e volta para a realidade. Além disso, Bastos (2005) comenta que a coda pode ter um caráter avaliativo: o falante pode fazer um comentário moral do evento, por exemplo se ele/ela narrou uma estória sobre um assalto e diz: "nunca mais ando com celular na rua à noite".

De acordo com Ribeiro e Pereira (2002), o enquadre acontece no momento em que estamos renegociando o contexto interacional. Dessa maneira, quando estamos em uma conversa com alguém ficamos atento ao que está sendo falado pelo interlocutor, para que não fiquemos perdidos ou "fora do assunto". Essa é a maneira que mantemos o contexto da interação ativa e não a mudamos. Todavia, as autoras asseveram que o contexto pode mudar por não estarmos familiarizados com o assunto ou por estarmos desconfortáveis, além disso esclarecem que esse conceito se introduz com Bateson ([1972], 2002), sendo visto como um "conceito psicológico e de natureza paradoxal". O autor afirma que para o ouvinte entender a mensagem, ela deve ser contextualizada, sobretudo saber como ela está enquadrada. Se estamos no restaurante, por exemplo, e o garçom assume um discurso racista, o enquadre, que antes era atendimento ao cliente se torna violência; um grupo de amigos em um bar conversando sobre 
assuntos aleatórios, e em algum momento um deles começa a explicar o que é preconceito linguístico, o enquadre, que antes era conversa entre amigos muda para o enquadre aula, pois não se trata mais de uma conversa espontânea, e em uma sala de aula virtual, o professor após apresentar o conteúdo começa a falar da vida pessoal, o ambiente sala de aula professor e alunos é enquadrado em colegas na sala de aula.

\section{Metodologia}

Esta pesquisa é qualitativa interpretativista e autoetnográfica, pois é baseada nas minhas vivências, na minha prática social a fim de construir entendimentos. Aqui, faço interpretações, uma vez que não existem verdades absolutas, mas sim reflexões baseadas em teorias para chegar em um possível entendimento, longe de um resultado objetivo (MINAYO, 2001).

No dia 19 de setembro de 2020, em que somente eu e minha mãe estávamos em casa, criei algumas perguntas a fim de começar uma conversa no momento da gravação do áudio. Expliquei que estava interessado em saber algumas questões sobre meu hábito de leitura, e então fomos para o quarto; ela de uma maneira bem confortável começou a conversar, trazendo experiências e histórias da vida dela, e uma pergunta levou à outra. Minha mãe não se limitou às perguntas respondendo "sim" ou "não" e "porque", pois ela até compartilhou histórias da época da escola. Todavia, selecionei o que foi relevante para a construção de entendimentos desta pesquisa, e para preservar a identidade dos nomes mencionados na gravação eu criei nomes fictícios para cada um deles.

Em se tratando de uma autorreflexão sobre a coletividade em que estou inserido (etno), a autoetnografia foi o método que julguei mais apropriado para a geração dos dados. Esse processo da própria inserção na comunidade causa questionamentos, o que faz o pesquisador refletir sobre si próprio (VERSIANI, 2005). Cabe aqui, nesta pesquisa, refletir sobre a minha prática de leitura e o que me levou ao desinteresse.

\section{Análise de dados}

No intuito de descobrir como era minha prática de leitura quando criança, abri um diálogo com a minha mãe, o qual foi gravado para buscar possíveis respostas. A partir do áudio, baseei-me em sua vivência e reflexões na construção dos dados. Embora eu tenha tido pouco contato com a minha mãe - ela sempre trabalhou muito para arcar com as despesas e não nos víamos diariamente -, atualmente o nosso contato é mais próximo. Então, aproveitei a oportunidade a fim de refletir o leitor que sou hoje no curso de Letras Português/Inglês. 
Tendo em mente que estamos inseridos numa pesquisa qualitativa, isto é, "ela trabalha com o universo de significados, motivos, aspirações, crenças, valores e atitudes" (MINAYO, 2001, p.21), sabemos que não podemos limitar o que o participante contribui na pesquisa, tudo deve ser levado em consideração. Nesse sentido, o que minha mãe compartilhou sobre a prática de leitura das pessoas que vivem no seu local de trabalho - as crianças das quais ela cuida e a mãe das crianças - e a sua própria prática na época da escola, contém informações que contribuem para a construção dos dados, uma vez que suas crenças e valores não devem ser descartados.

\section{1.“Gibi é o começo!"}

Lembrando que a primeira leitura se faz na realidade do indivíduo, com base em sua “inteligência de mundo" (FREIRE, 1989), fico me indagando como era meu mundo particular daquela época, como eu enxergava o contexto em que eu estava inserido, para que eu chegasse depois na decodificação das palavras. Na verdade, não me recordo de ter lido gibi na fase de alfabetização, porém me vêm lembranças de assistir fitas no vídeo cassete, como foi dito pela minha mãe na linha 8 . A relação que eu fazia da minha realidade com a leitura poderia ser feita com as imagens do vídeo, e não pela decodificação de palavras escritas.

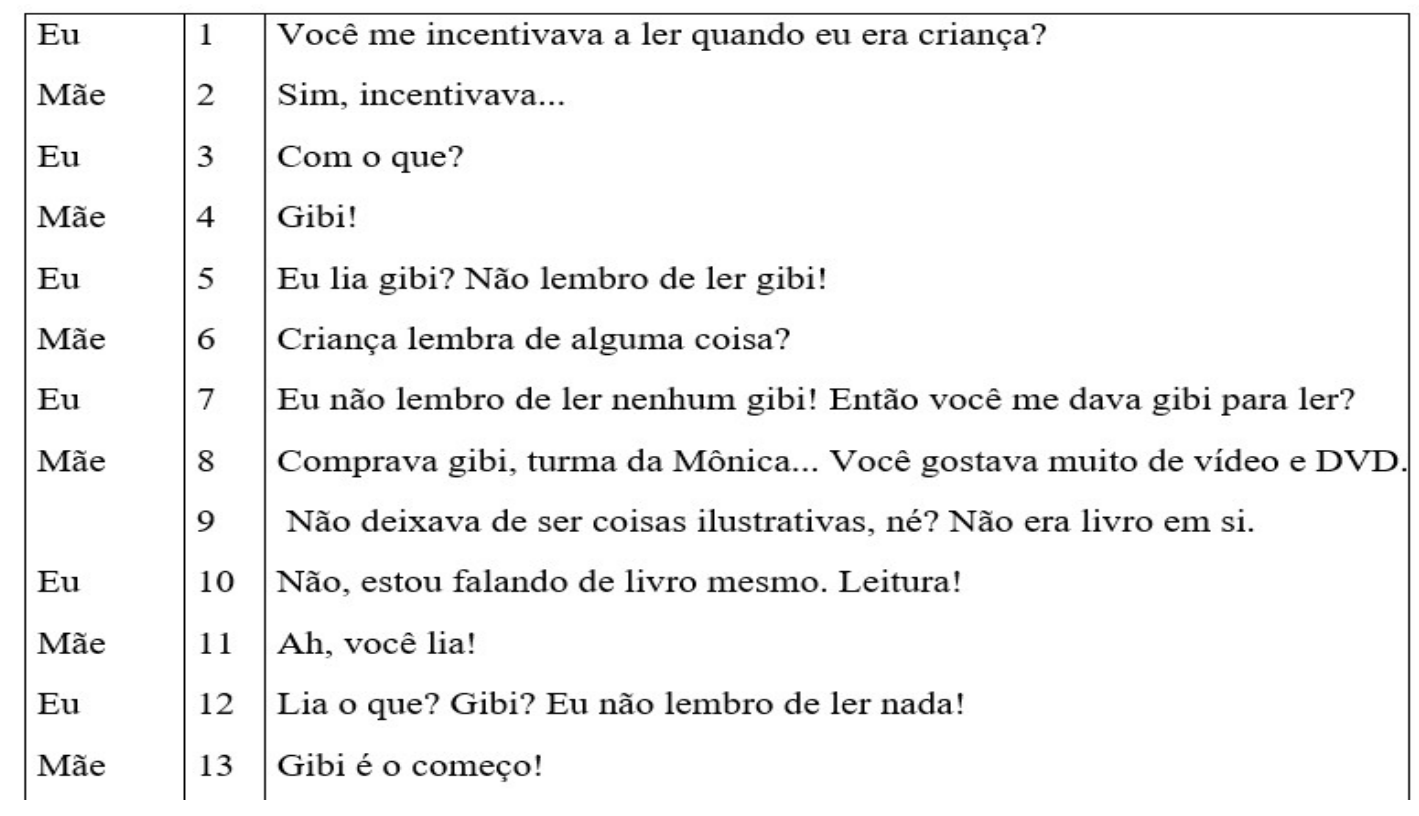

Tabela 1

Primeiramente, podemos observar na Tabela 1 que há um ponto que sustenta toda a conversa, uma vez que o diálogo gira em torno do assunto "leitura". Eu fiquei surpreso quando 
minha mãe diz que eu lia gibi (linha 7), essa parte da narrativa foi algo que me chamou a atenção - se tratando de uma criança que não tinha interesse pela leitura -, por isso a narrativa se torna contável. O enquadre "conversa entre mãe e filho sobre leitura" muda para "conversa entre mãe e filho sobre vídeos e imagens" (linhas 8 e 9), quando minha mãe fala que eu gostava bastante de vídeo e DVD, mas rapidamente, eu reenquadro voltando para o assunto "leitura" (linha 10). Já na última linha, o interlocutor (mãe) finaliza a conversa com caráter avaliativo, o que se refere à coda, podendo inferir que a criança começa com pequenas leituras para depois avançar.

A fala de minha mãe na linha 13 instigou-me a pensar que, realmente, tudo tem um começo. Segundo Vygotsky (1998, 2008, apud Orlando e Leite, 2018), os seres humanos se constituem na interação e vivenciam uma cultura - temos nesta pesquisa a leitura como uma prática cultural - que é internalizada por meio deste contato social. Supõe-se que o começo é a interação e depois o que é externo ao indivíduo, nesse caso a prática de leitura, é internalizado.

Diante do exposto, na linha 5, digo que não me recordo de ter lido gibi, o que se pode inferir que não internalizei o que vivenciei. Por outro lado, observo que essa foi a iniciativa que minha mãe encontrou para me motivar a ler, apesar da comunidade que eu estava inserido não ter a leitura como uma prioridade. A abordagem histórico-cultural de Chartier (1985, 1990), exposta por Orlando e Leite (2018), explica que a leitura particular pode ser interferida pelo costume da comunidade. Nessa perspectiva, mesmo que eu tivesse desejos particulares, como por exemplo a vontade de ler em busca de conhecimentos, as pessoas ao meu redor que não possuíam hábito de leitura podem ter me influenciado, neste caso, a não me engajar nessa prática.

\subsection{Alguém mais da família me incentivava a ler, a não ser você?}

\begin{tabular}{|l|l|l|} 
Eu & 19 & Eu lembro também que no colégio tinha feira do livro. Lembra? \\
Mãe & 20 & Sim! Na escola que eu estudava tinha biblioteca. \\
Mãe & 21 & Eu nunca comprava nada, porque eu não gostava. \\
& 22 & Mas eu comprei uns livros, acho que até se estragou devido você não \\
& 23 & gostar mesmo. Nossa, aqueles livros foram caríssimos! Ficou na casa de \\
24 & Bica. Era uns livros ilustrativos, tinha várias histórias. Tinha...da \\
Eu & 25 & Narizinho, me lembro, do Sítio do Pica-pau amarelo. Nossa... eram mais \\
Mãe & 26 & de dez livros, todos escritos e pintados a óleo. \\
& 28 & A óleo? \\
Eu & 29 & Era...não sei como que se fala, mas eram livros que muitas famílias \\
& 30 & Alguém mais da família me incentivava a ler, a não ser você? \\
\hline
\end{tabular}




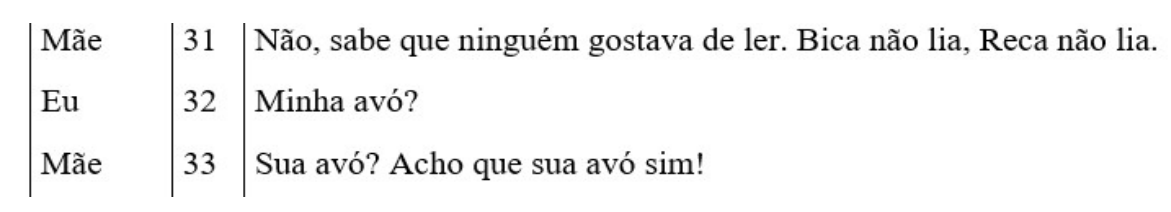

Tabela 2

Para que possamos entender o contexto do diálogo, selecionei as linhas que estão presente na Tabela 2, mas o nosso foco será nas linhas 19 e 20, nas quais explicitam a mudança do enquadre. Podemos notar que quando faço o seguinte comentário: "eu lembro também que no colégio tinha feira do livro. Lembra?" minha mãe (a falante) muda o enquadre. Mais uma vez vale ressaltar, se o interlocutor não estiver atento ao contexto interacional o enquadre muda. $\mathrm{Na}$ linha 21, eu concluo sobre o assunto da biblioteca, porém na linha 22, a conversa é enquadrada em "livros que minha mãe comprou, que não são os da feira", no qual me deixei levar na conversa, porque eu estava interessado em saber mais.

Da linha 22 até a 26, entendo como a ação complicadora, pois há uma sequência temporal, as orações estão em ordem e no passado. Além disso, a narrativa é contável, porque tudo que o interlocutor (mãe) relata é novo para mim e fico curioso para saber, e o ponto diz respeito ao contexto "livro". Minha mãe não traz um resumo do evento (linha 22), mas complementa sobre eu não comprar livros na feira do colégio, relatando o que aconteceu quando comprou os que não são da feira, apontando o lugar onde os livros talvez ficaram (casa de Bica), o tempo (passado), as pessoas envolvidas (eu, ela e Bica) e as circunstâncias, "aqueles livros foram caríssimos". Percebe-se que ela contextualizou o evento, fez uma orientação.

A avaliação acontece (linha 25) quando o interlocutor transmite uma carga dramática utilizando a interjeição "Nossa..." ao relatar que eram mais de dez livros. Com isso, indica o ponto, pois não desvia o assunto, e a reportabilidade da narrativa, ao me causar curiosidade e por eu acreditar que é algo fora da normalidade. Em seguida, eu queria saber se, de fato, era pintado a óleo, porque eu não tinha visto livros dessa maneira.

Por meio do comentário feito na linha 31, é possível entender que a comunidade interfere no particular dos participantes. Aqui, gostaria de alinhar-me à teoria de Wallon (1968), a qual Grotta (2000) afirma que a aquisição de conhecimento por meio da leitura possui vínculos afetivos, porque são as necessidades que o indivíduo possui que o leva a ler. Nessa perspectiva, minhas tias (Bica e Reca) provavelmente não tiveram motivos, nem desejos que as levaram a ler, o que se pode inferir que elas tiveram uma experiência negativa que as mantiveram distante da prática de leitura. Logo, voltando à ideia de que a comunidade interfere na liberdade do leitor (CHARTIER, 1985, 1990), é possível depreender que minhas tias, que 
me criaram e constituíam uma parte das pessoas com quem eu convivia, me influenciaram de alguma forma, porque a ausência de leitura faz parte da cultura daquela comunidade e, não havia motivos que as levassem a ter esse hábito.

\section{3 "A escola deles incentiva e os pais também"}

Minha mãe compartilhou tantos fragmentos de narrativas dela, e que fiquei interessado em saber um pouco sobre seus hábitos de leitura na infância. $\mathrm{O}$ assunto deveria ser voltado para mim, mas aconteceu de em alguns momentos de nossa conversa, mudarmos o foco do assunto. Conforme já especificado, tudo mencionado pelos participantes em uma interação comunicativa tem uma função.

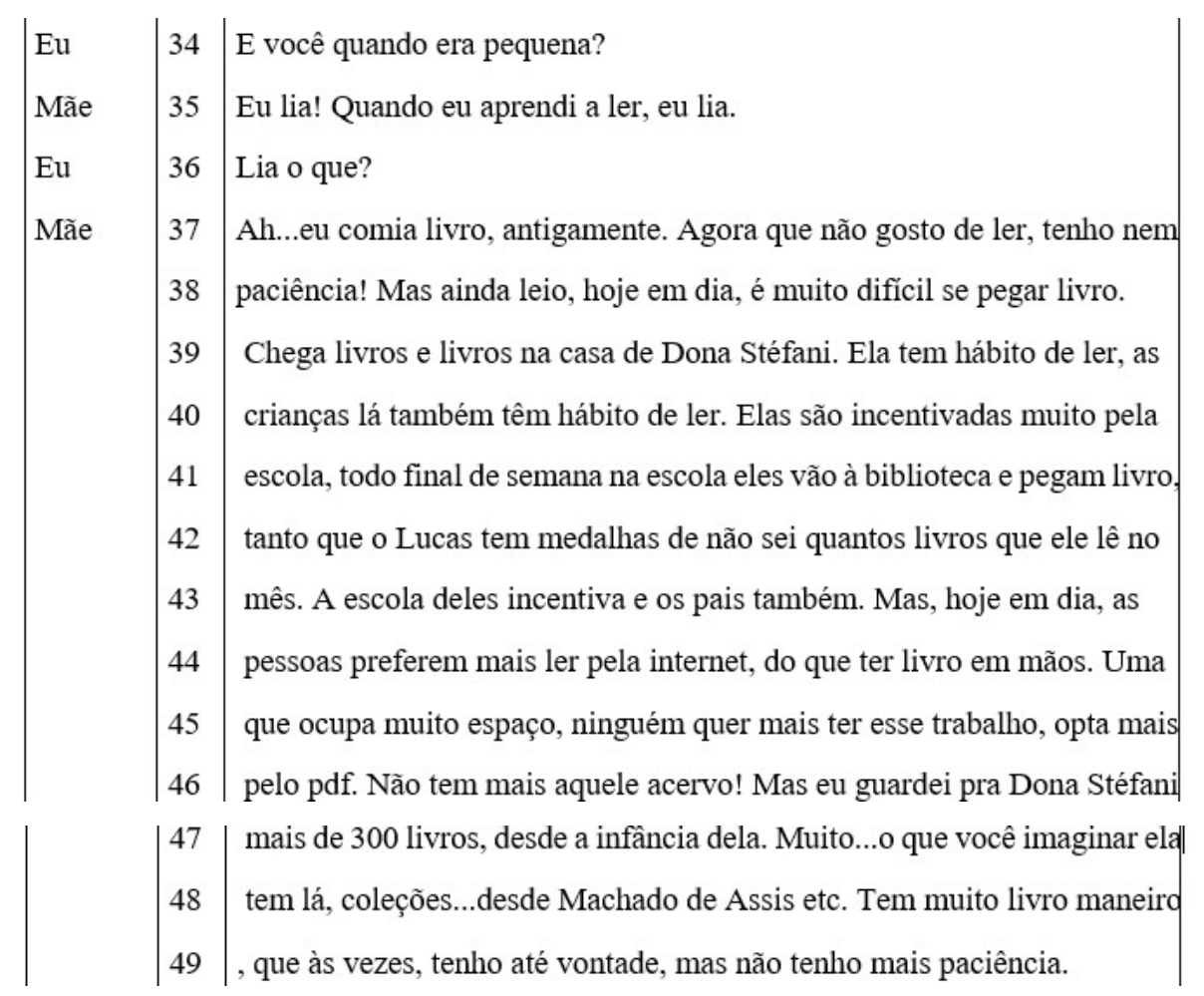

\section{Tabela 3}

Dentro do contexto da leitura, minha mãe reportou experiências dela, das crianças que ela cuida e da mãe delas. Podemos entender que a narrativa tem o ponto, porque está dentro do contexto e é reportável. Como podemos observar na Tabela 3 das linhas 39 e 42, o fato de chegarem muitos livros na casa de Dona Stéfani nos chama a atenção, porque não é comum as pessoas encomendarem muitos livros, e o Lucas ganha medalhas por livros já lidos, o que também está fora da normalidade. Esses fatos chamam a atenção do ouvinte por ser um evento extraordinário e por não estarem longe da realidade. 
Nas linhas 37 e 38, é possível detectar o contexto do evento; minha mãe começa falando do passado, quando ela teve um contato muito próximo com a leitura. Ela inicia seu relato com um comentário que resume a narrativa "eu comia livro, antigamente", e segue narrando suas experiências, tanto no presente como passado, pois podemos inferir que ela "comia" livros e agora não mais. Pode-se compreender a ação complicadora aqui, numa sequência de enunciados, mas que não são todas reportadas no passado. Levei em consideração que Bastos (2005) diz que os verbos são "tipicamente" reportados no passado e os "enunciados temporalmente ordenados". Portanto, considerei a sequência de passado e presente da narrativa.

$\mathrm{Na}$ linha 48, é enfatizado que há variedades de livros na casa de Dona Stéfani, essa é a avaliação encaixada que minha mãe faz ao reportar: "tem muito livro maneiro", utilizando o intensificador "muito". A atitude da minha mãe a respeito do evento é positiva; todavia, na linha 37, ela introduz dizendo "não gosto de ler" e faz uma avaliação externa do ponto da narrativa. A coda acontece na linha 49, ela diz: "não tenho mais paciência" e encerra a narrativa fazendo um comentário moral, no qual podemos entender que mesmo Dona Stéfani tendo muitos livros e ela já ter tido um hábito de leitura, chegou à conclusão que não quer mais ler.

Da linha 37 em diante, minha mãe é responsável por toda a fala, sendo assim muda de enquadre mais de uma vez. Primeiro, ela assume o enquadre de quando ela começou a ler (linha 37), comentando de uma forma breve, depois se enquadra no hábito de leitura das crianças e da mãe delas (linha 39), dizendo que a escola e os pais as incentivam, após isso enquadra a conversa sobre as pessoas que leem pela internet (linha 44), e por fim, se enquadre ao hábito de leitura da Dona Stéfani (linha 46).

\section{Considerações Finais}

Adotando uma atitude reflexiva de tentar entender o porquê do meu desinteresse pela leitura, pude sustentar-me à Prática Exploratória, pois ela incentiva que os docentes em formação inicial busquem olhar para o processo de entendimento com uma postura reflexiva. Dessa maneira, não há uma mudança de técnica, mas sim uma reflexão sobre o meu hábito de leitura como uma maneira de ressignificá-lo e de aprofundar os entendimentos. $O$ ato de pensar sobre essa dificuldade, pode ser visto como uma maneira de olhar para a minha futura prática docente.

Portanto, a busca pela qualidade de vida pode ser estimulada ao passo que procuro entender as minhas questões individuais, para que eu as amadureça e incentive os futuros estudantes a serem críticos e terem um olhar investigativo dentro e fora da sala de aula. 


\section{REFERÊNCIAS BIBLIOGRÁFICAS}

ALLWRIGHT, D; HANKS, J. 2009. The developing language learner - an introduction to exploratory practice. Londres: Palgrave Macmillan.

BATESON, G. Uma Teoria sobre Brincadeira e Fantasia. In: B.T. Ribeiro \& P. Garcez [Eds.]. Sociolinguística Interacional. São Paulo: Loyola. [1972] 2002. p. 85-105.

BASTOS, L. C. Contando estórias em contextos espontâneos e institucionais - uma introdução ao estudo da narrativa. Calidoscópio (UNISINOS), São Leopoldo, RGS, v. 3, n. 2 , p. 74-87, 2005.

CHARTIER, R. A história cultural: entre práticas e representações. Lisboa: Difel, 1990.

FREIRE, P. A importância do ato de ler. 23. ed. São Paulo: Cortez, 1989.

GROTTA, E. C. B. Processo de formação do leitor: relato e análise de quatro histórias de vida. Dissertação de mestrado - Universidade Estadual de Campinas Faculdade de Educação, São Paulo, 2000.

Grupo da Prática Exploratória. Por que trabalhar para entender a vida na sala de aula? histórias do Grupo da Prática Exploratória. Grupo da Prática Exploratória. Rio de Janeiro: 2020. Disponível em:

$<\underline{\text { http://www.pucrio.br/ensinopesq/ccg/licenciaturas/download/ebook_por-que trabalhar-para- }}$ entender-a-vida-em-sala-de-aula.pdf $>$. Acesso em: 10 dez. 2020.

LABOV, W. Some further steps in narrative analysis. Journal of Narrative and Life History, 7 (1-4): 395-413, 1997.

LABOV, W. The transformation of experience in narrative syntax. In: W. LABOV, Language in the inner city. Philadelphia, University of Philadelphia Press, p. 354-396, 1972.

LABOV, W.; WALETZKY, J. Narrative Analysis: oral versions of personal experience. In: J. HELM (org.). Essays on the verbal and visual arts. Seatle, University of Washington Press, p. 12-14, 1967.

MILLER, I.K. et al. Prática Exploratória: Questões e Desafios. In Gil, G. \& Abrahão, M.H. (Orgs.). A formação do professor de línguas: os desafios do formador. Editora Pontes, 2008, p. 145-165.

MINAYO, M. C. S. (Org.). Pesquisa Social. Teoria, método e criatividade. 18 ed. Petrópolis: Vozes, 2001.

ORLANDO, I.; LEITE, S. Formação de leitores: a dimensão afetiva na mediação da família. Scielo, São Paulo, n. 3, v. 22, p. 511-518, 2018.

PINKER, S. Guia de Escrita: como conceber um texto com clareza, precisão e elegância. São Paulo: Editora Contexto, 2016.

RIBEIRO, B. T.; PEREIRA, M. G. D. A noção de contexto na análise do discurso. Veredas Rev. Est. Ling. Juiz de Fora, v. 6, n. 2, p. 49-67, 2002. 
VERSIANI, D. B. Autoetnografias: conceitos alternativos em construção. Rio de Janeiro: 7Letras, 2005.

VYGOTSKY, L. S. A formação social da mente. São Paulo: Martins Fontes, 1998. Pensamento e linguagem. São Paulo: Martins Fontes, 2008.

WALLON, H. A evolução psicológica da criança. Lisboa: Edições 70, 1968. Do ato ao pensamento. Rio de Janeiro: Editora Vozes, 2008. 